\title{
New Website for The Canadian Journal of Neurological Sciences
}

Can. J. Neurol. Sci. 2002; 29: 301

The Canadian Congress of Neurological Sciences (CCNS) was established as a nonprofit professional organization dedicated to the advancement of knowledge, patient care and collegiality among health care professionals and research scientists working in all branches of the neurological sciences. The main activities of the CCNS have been the organization and running of the annual scientific meeting for its member societies/associations and the publishing of The Canadian Journal of Neurological Sciences (CJNS), a journal which has been jointly owned by the member societies since 1981 .

With the advent of the electronic era, changes must occur if the CCNS and CJNS are to continue to play a meaningful role. It is no longer enough to publish a top quality journal or organize high caliber meetings. Professional organizations are now also expected to play an active role in the continuing medical education (CME) of their members.

The electronic committee of Canadian Congress of Neurological Sciences and The Canadian Journal of Neurological Sciences was established to advise, facilitate and monitor the development and implementation of electronic communication for both organizations. Within the next few years, it is envisioned that an electronic system will be in place that will allow for the rapid electronic dispersion of scientific advancements in Canadian clinical neurosciences to the practicing neurologist and neurosurgeons. This system will also be able to meet their continuing medical education needs; act as the principal communication between physician and the member societies/association of the Canadian Congress of Neurological Sciences; and be the resource to which patients and their families can be referred by their treating physicians to obtain reliable information about various neurological disorders. Several steps will be necessary in order to realize this vision. Some of these steps have already been completed. Others are in the development stages and will be gradually added. The purpose of this communication is to inform the members of the societies/associations that constitute the Canadian Congress of Canadian Neurological Sciences about this work in progress.

Plans for updating the separate websites for the Canadian Congress of Neurological Sciences and The Canadian Journal of Neurological Sciences have been completed. Recently the new website for The Canadian Journal of Neurological Sciences became operational (www.cjns.org). This site contains the contents, abstracts, articles and general information about The Canadian Journal of Neurological Sciences. It allows for rapid online search and downloading of articles published in the Journal. Cross-referencing of articles referenced in the Journal article has been done through a contractual arrangement with MetaPress, an online services company. This service allows online linkage to abstracts of the referenced article published in other journals that are online. During the first year, the ability to retrieve and download articles on the Journal website will be free, however, the following year free retrieval will be a privilege limited to members of a member society/association of the Canadian Congress of Neurological Sciences or paid subscribers to The Canadian Journal of Neurological Sciences. This service will be available to others for a fee per article retrieved.

Revisions to the website for the Canadian Congress of Neurological Sciences are underway. Parts of the site should be operational in the very near future. A high priority item for this website has been the development of online CME limited to members or member societies/associations. A maintenance of certification (MOC) approved online learning program based on journal articles is being developed. Articles that have been designated for CME credit will be identified in the table of contents of the Journal. After reading the article, the member would log on the CCNS website and answer questions about the article; submit the answers, and receive the correct answers and MOC credits. This is then downloaded and kept as a record of the learning experience. Articles to be used in this process will include review articles, clinical pathological conferences and neurological imaging studies. It is anticipated that this site will be available for members to access in early 2003.

In addition to the development of CME experience based on articles published in the Journal, it is anticipated that links to other MOC approved online learning sites dedicated to neurological or neurosurgical learning will also be made available in the near future.

In addition, the CCNS website will have areas which can be accessed by the public such as general information about the Congress of Neurological Sciences, its member societies, the annual meeting, information about residency programs and fellowships.

Each of the societies/associations that belong to the Canadian Congress of Neurological Sciences has been asked to develop both a public access area as well as members-only website sections that contain specific information about their society/association.

We hope that the members find these changes as exciting as we do. We would like to hear your comments and ideas for future direction in the development of electronic communications for both the Canadian Congress of Neurological Sciences and The Canadian Journal of Neurological Sciences. Please feel to email your suggestions to brains@ccns.org.

Daniel Keene, Ottawa, ON

Douglas W. Zochodne, Calgary, $A B$

Sally Gregg Calgary, $A B$ 